\title{
Effect of Annealing Temperature on Structural, Morphological, Optical and Electrical Properties of Spray Deposited $\mathrm{V}_{2} \mathrm{O}_{5}$ Thin Films
}

\author{
Vijayakumar YELSANI ${ }^{1}{ }^{*}$, Nagaraju POTHUKANURI ${ }^{1}$, Uday Bhasker SONTU ${ }^{2}$, \\ Veeraswamy YARAGANI ${ }^{3}$, Ramana Reddy MUSKU VENKATA ${ }^{2}$
}

\author{
${ }^{1}$ Department of Physics, CMR Technical Campus, Hyderabad, Telangana, India \\ ${ }^{2}$ Thin Films and Nano Materials Research Laboratory, Department of Physics, Osmania University, Hyderabad, Telangana, \\ India \\ ${ }^{3}$ Institute of Aeronautical Engineering, Dundigal, Hyderabad, Telangana, India \\ crossref http://dx.doi.org/10.5755/j01.ms.25.1.18492
}

Received 29 June 2017; accepted 13 January 2018

\begin{abstract}
Nanostructured vanadium pentoxide $\left(\mathrm{V}_{2} \mathrm{O}_{5}\right)$ thin films have been deposited by a simple and cost-effective spray pyrolysis technique (SPT) at substrate temperature $300{ }^{\circ} \mathrm{C}$ and post annealed at atmospheric conditions in the temperature range from $300{ }^{\circ} \mathrm{C}$ to $500{ }^{\circ} \mathrm{C}$ at a constant rate of heating. The influence of post annealing heat treatment on the crystallization of $\mathrm{V}_{2} \mathrm{O}_{5}$ has been investigated. Films were characterized structurally by X-ray diffraction, morphologically by Scanning electron microscopy, optically using UV-Vis spectrophotometer, electrical characterization using Hall probe and Raman spectroscopy has been carried out for phase confirmation. X-ray diffraction analysis (XRD) revealed that, as deposited films were orthorhombic structures with a preferential orientation along $\left(\begin{array}{lll}0 & 0 & 1\end{array}\right)$ direction. Moreover, it was observed that crystallite size increases from $22 \mathrm{~nm}$ to $56 \mathrm{~nm}$ with increase in annealing temperature. Optical properties of these samples were studied in the wavelength range $300-1000 \mathrm{~nm}$. Raman spectrum confirms the layered structure of $\mathrm{V}_{2} \mathrm{O}_{5}$ thin films. Hall Effect measurements indicate that the change in carrier concentration with increase in annealing temperature. Keywords: $\mathrm{V}_{2} \mathrm{O}_{5}$, annealing temperature, Raman spectroscopy, carrier density.
\end{abstract}

\section{INTRODUCTION}

Vanadium pentoxide $\left(\mathrm{V}_{2} \mathrm{O}_{5}\right)$ is the most stable phase in $\mathrm{V}-\mathrm{O}$ system and it also exhibits multivalancy, layered structure, wide optical band gap with good electrochemical and thermo chromic properties [1]. Especially, $\mathrm{V}_{2} \mathrm{O}_{5}$ in thin film form has attracted considerable interest due to their wide range of applications. Compared to bulk, $\mathrm{V}_{2} \mathrm{O}_{5}$ in nano thin film form substantially improve the performance of devices for energy storage and sensing due to their distinct physical and chemical properties because of their large surface area and with unique morphology [2]. The $\mathrm{V}_{2} \mathrm{O}_{5}$ thin films have been prepared by different techniques such as RF-sputtering [3], dc-magnetron sputtering [4], flash evaporation [5], spin coating [6], dip coating [7] and pulsed laser deposition [8]. However, a technique with a relatively low cost, good stoichiometry and large area, the spray pyrolysis has been used to prepare $\mathrm{V}_{2} \mathrm{O}_{5}$ thin films.

In the previous work [9], we have undertaken an extensive study of sprayed $\mathrm{V}_{2} \mathrm{O}_{5}$ thin films, i.e., optimization of the growth parameters, chemical composition, microstructural and optical properties. Annealing temperature critically effects the crystallinity and other material properties of the as deposited films. When the films are annealed, three processes may take place; recovery, recrystallization and grain growth. To study the effect of annealing temperature, as deposited films are treated at different annealing temperatures. This research deals with the effect of annealing temperature on microstructural, optical and electrical properties of $\mathrm{V}_{2} \mathrm{O}_{5}$ thin films.

\section{EXPERIMENTAL DETAILS}

Ultrasonically cleaned glass substrates (Blue star, India) were used to deposit $\mathrm{V}_{2} \mathrm{O}_{5}$ thin films with optimized parameters (Nozzle to substrate distance $(\mathrm{NSD})=30 \mathrm{~cm}$, substrate temperature $\left(T_{s}\right)=300{ }^{\circ} \mathrm{C}, 0.1 \mathrm{M}$ of ammonium vanadate and water as solvent) has been chosen for annealing treatment. This film was treated at different annealing temperatures such as $300{ }^{\circ} \mathrm{C}, 400{ }^{\circ} \mathrm{C}$ and $500{ }^{\circ} \mathrm{C}$ per one hour at a constant rate of heating $5^{\circ} \mathrm{C} / \mathrm{min}$.

To examine the crystalline structure of the films, Bruker D8 Advance, USA X-ray diffractometer (XRD) using Cu $\mathrm{K}_{\alpha}$ radiation $(\lambda=1.54059 \AA)$ was employed. The absorbance spectra of all the films were recorded by a UV - Vis 3000 spectrophotometer, Lab India Analytical Instruments. Raman scattering spectra were recorded at room temperature using Renishaw In Via micro Raman spectrometer in the wave number range $100-1000 \mathrm{~cm}^{-1}$ with a $532 \mathrm{~nm}$ laser. The surface morphology of the films was observed with scanning electron microscope (Carl ZEISS EVO 18, Germany). Carrier density and resistivity were measured with Hall Effect measurement system (HMS-3000, ECOPIA) under a magnetic field of $0.5 \mathrm{~T}$ at room temperature.

\footnotetext{
* Corresponding author. Tel.: +91-9849460807.

E-mail address: yelsani.vijay@gmail.com (Y. Vijayakumar)
} 


\section{RESULTS AND DISCUSSION}

All the as deposited and annealed films were pin hole free. Adhesion of the film was tested with scotch tape and found to well adhered to substrates. Thickness of the films were found to be $950 \mathrm{~nm}$.

Fig. 1 shows the X-ray diffraction (XRD) patterns of $\mathrm{V}_{2} \mathrm{O}_{5}$ thin films annealed at different temperatures $\left(T_{a}\right)$ and as deposited $\mathrm{V}_{2} \mathrm{O}_{5}$ films were found to be polycrystalline nature. The peaks observed at $2 \theta=15.3^{\circ}, 20.2^{\circ} .26 .1^{\circ}$, $30.9^{\circ}, 41.1^{\circ}, 51.1^{\circ}$ were corresponding to (200), (001), (110), (301), (002) and (020) planes respectively. This pattern confirmed the formation of single phase $\mathrm{V}_{2} \mathrm{O}_{5}$ films with orthorhombic structure and well-defined layered structure and agreed with the JCPDS Card No. 89-2482. After annealing the films, the intensity of the $\left(\begin{array}{lll}0 & 0 & 1\end{array}\right)$ peak found to decrease with annealing temperatures to $500{ }^{\circ} \mathrm{C}$ and the intensity of (110) peak increased at the same time. This might be due to the recrystallization process triggered by the increased annealing temperature. This could be corroborated from the appearance of new peaks (200), (301), (111) and (112) reflections for the films annealed at different temperatures [10]. Crystallite size of the films was estimated using Sherrer's equation; it is observed that crystallite size increases with increase in annealing temperature. The values of crystallite sizes for different annealing temperatures are shown in Table I. The increase in crystallite size may be due to the coalescence process that takes place by annealing the films [11].

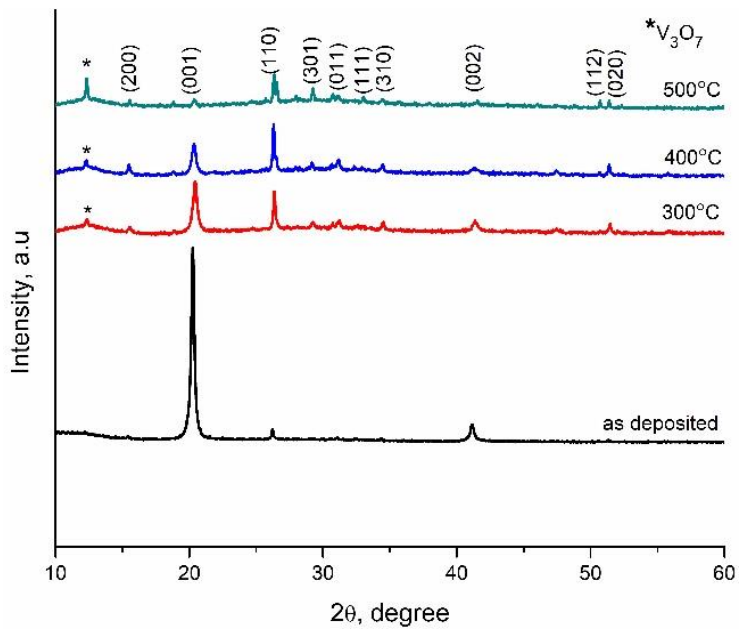

Fig. 1. XRD patterns of $\mathrm{V}_{2} \mathrm{O}_{5}$ thin films at different annealing temperatures

Table 1. Crystallite sizes of $\mathrm{V}_{2} \mathrm{O}_{5}$ thin films annealed at different temperatures

\begin{tabular}{|c|c|}
\hline Annealing temperature, ${ }^{\circ} \mathrm{C}$ & Crystallite size, $\mathrm{nm}$ \\
\hline As deposited & 22 \\
\hline 300 & 39 \\
\hline 400 & 46 \\
\hline 500 & 56 \\
\hline
\end{tabular}

SEM images of $\mathrm{V}_{2} \mathrm{O}_{5}$ thin films annealed at different temperatures are given in Fig. 2. As deposited $\mathrm{V}_{2} \mathrm{O}_{5}$ film shows the formation of fiber like morphology (Fig. 2 a). As the annealing temperature was increased, the width of the fiber like structure (Fig. 2 b) began to disappear.

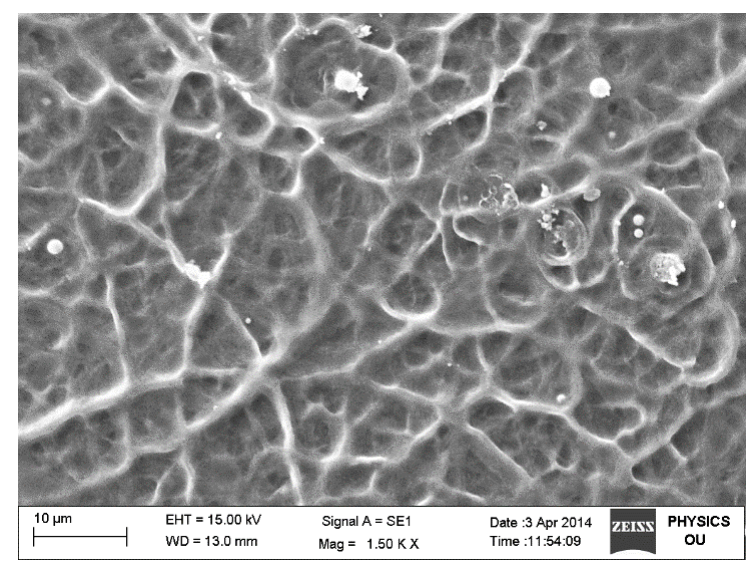

a

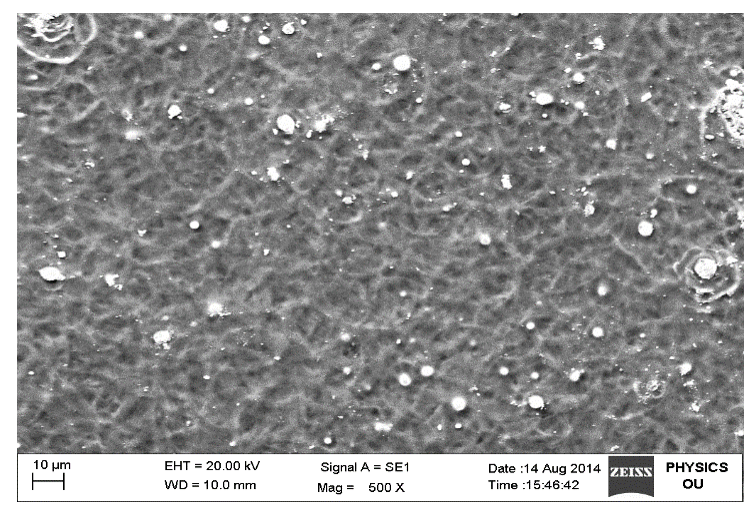

$\mathrm{b}$

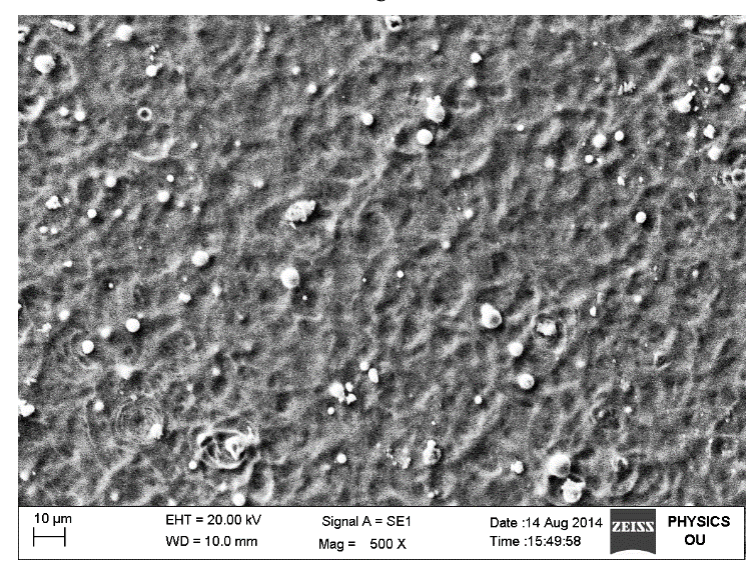

c

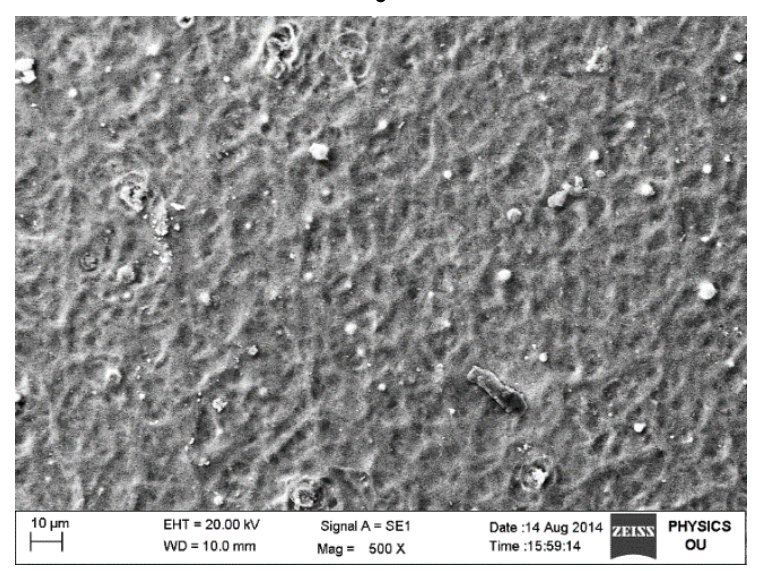

d

Fig. 2. SEM images of $\mathrm{V}_{2} \mathrm{O}_{5}$ films deposited at different annealing temperatures: $\mathrm{a}$-as deposited; $\mathrm{b}-300{ }^{\circ} \mathrm{C} ; \mathrm{c}-400{ }^{\circ} \mathrm{C}$; $\mathrm{d}-500{ }^{\circ} \mathrm{C}$ 
At higher annealing temperatures (Fig. 2 d), the fibers disappeared due to the recrystallization of the material. The Raman spectra of $\mathrm{V}_{2} \mathrm{O}_{5}$ films annealed at different temperatures are shown in Fig. 3.

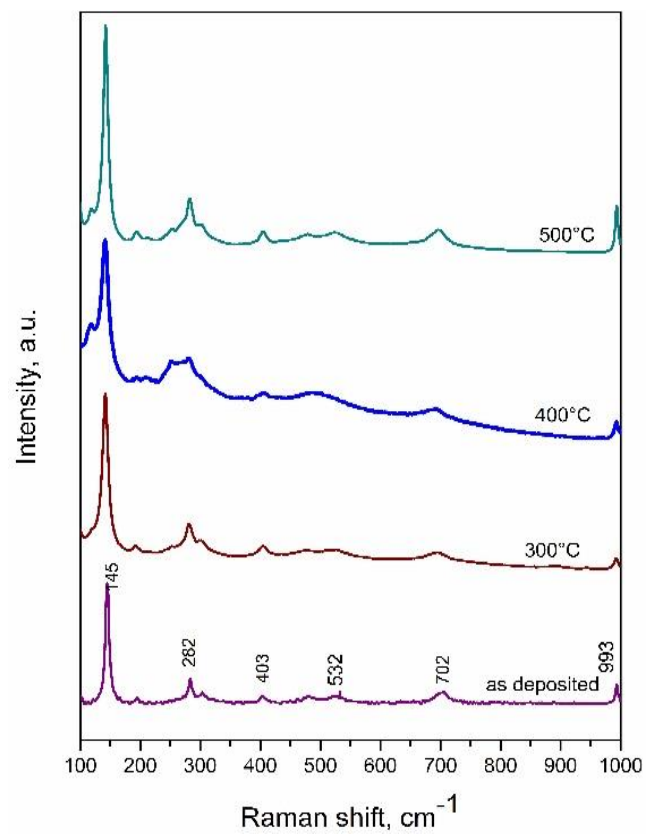

Fig. 3. Raman spectra of $\mathrm{V}_{2} \mathrm{O}_{5}$ films deposited at different annealing temperatures

From the spectra, it can be seen that structural properties of the films vary with the annealing temperatures. A spectrum of the deposited films is more intense and sharper due to the crystalline nature.

As the annealing temperature increases, the bands observed were are broadened and shifted. This may be due to the structural reorganization of the film. All observed bands are assigned and tabulated in Table 2 [12].

Table 2. Assignment of Raman bands

\begin{tabular}{|c|l|}
\hline $\begin{array}{c}\text { Raman bands, } \\
\mathrm{cm}^{-1}\end{array}$ & \multicolumn{1}{c|}{ Assignment } \\
\hline 145 & $\begin{array}{l}\text { The skeleton bent vibration, evidence for the } \\
\text { layer-type structure }\end{array}$ \\
\hline 282 & Bending vibrations of the $\mathrm{O}_{\mathrm{C}-\mathrm{V}-\mathrm{O}_{\mathrm{B}} \text { bond }}$ \\
\hline 403 & The bending vibration of $\mathrm{V}-\mathrm{O}_{\mathrm{B}}-\mathrm{V}$ bond \\
\hline 532 & stretching vibration of the $\mathrm{V}-\mathrm{O}_{\mathrm{B}}$ \\
\hline 702 & Stretching vibration of $\mathrm{V}-\mathrm{O}_{\mathrm{C}}$ \\
\hline 993 & Terminal oxygen $(\mathrm{V}=\mathrm{O})$ stretching mode \\
\hline
\end{tabular}

These bands show perfect evidence of the formation layer structure of $\mathrm{V}_{2} \mathrm{O}_{5}$ thin films.

The optical absorbance spectra of the films as deposited and annealed at different temperatures are shown in Fig. 4. The absorbance was found to increase with an increase in the annealing temperature and annealed films showed a high absorbance which indicated the formation of structural reorganization with an increase in grain size [13]. The direct band gap $\left(E_{g}\right)$ of the films was calculated from the extrapolation of the linear part of the $(\alpha h v)^{2}$ versus hv curve to zero (Fig. 5). The calculated values of the optical band gap $\left(E_{g}\right)$ were $2.4 \mathrm{eV}, 2.31 \mathrm{eV}, 2.25 \mathrm{eV}$ and $2.14 \mathrm{eV}$ for the films as deposited and annealed at different temperatures $300{ }^{\circ} \mathrm{C}, 400{ }^{\circ} \mathrm{C}$ and $500{ }^{\circ} \mathrm{C}$ respectively.

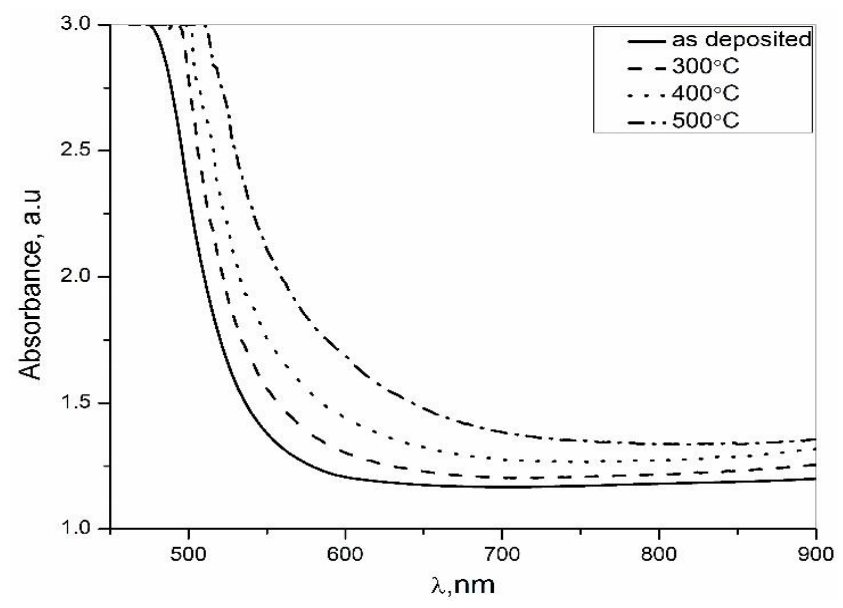

Fig. 4. Absorbance of the $\mathrm{V}_{2} \mathrm{O}_{5}$ films with wavelength for different annealing temperatures

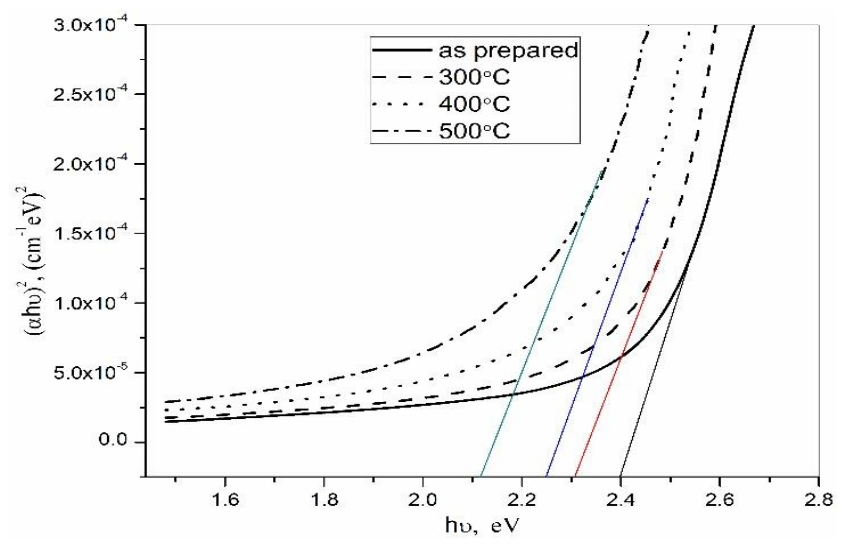

Fig. 5. $(\alpha h v)^{2} v / s$ hv at different annealing temperatures

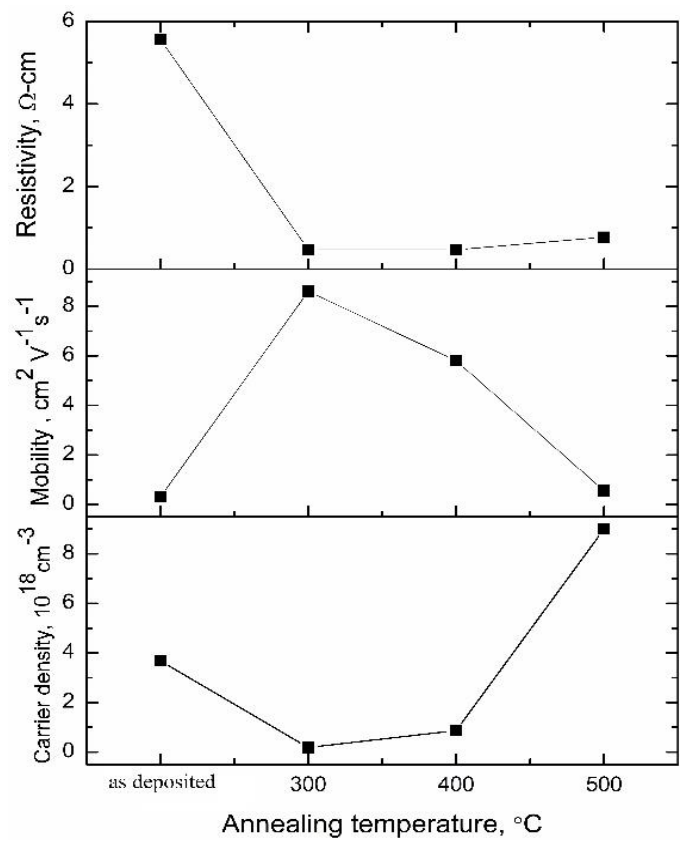

Fig. 6. The resistivity, carrier mobility and density of the $\mathrm{V}_{2} \mathrm{O}_{5}$ films

When the film was annealed at higher temperature, the energy gap is shifted to lower photon energy and it clearly indicates that the energy gap decreases as the annealing temperature increases. The microstructure changes caused by annealing treatment can be attributed to decrease in 
optical band gap. Similar observations are reported in $\mathrm{V}_{2} \mathrm{O}_{5}$ films deposited by dip coating technique [14], it can also be explained in terms of quantum-size effect in which the films with large size crystallites. The electrical properties of the films as deposited and annealed at different temperatures of $\mathrm{V}_{2} \mathrm{O}_{5}$ thin films measured by van der Pauw Hall measurement system are shown in Fig. 6.

\section{CONCLUSIONS}

$\mathrm{V}_{2} \mathrm{O}_{5}$ thin films have been synthesized by a simple spray pyrolysis technique. As deposited films exhibited an orthorhombic structure with fiber like morphology. The optical band has decreased with increasing annealing temperature. The morphology of the thin films has been varied with an increase in the annealing temperature. The carrier density and resistivity have been varied with an increase in the annealing temperatures.

\section{Acknowledgments}

Y. Vijayakumar and P. Nagaraju express sincere gratitude to Ch. Gopal Reddy, Chairman, Dr. A. Raji Reddy, Director, CMR Technical Campus for their constant encouragement during the present work.

\section{REFERENCES}

1. Beke, $\mathbf{S}$. A Review of the Growth of $\mathrm{V}_{2} \mathrm{O}_{5}$ Films from 1885 to 2010 Thin Solid Films 519 2011: pp. $1761-1771$. https://doi.org/10.1016/j.tsf.2010.11.001

2. Vasanth Raj, D., Ponpandian, N., Mangalaraj, D., Viswanathan, C. Effect of Annealing and Electrochemical Properties of Sol-Gel Dip Coated Nanocrystalline $\mathrm{V}_{2} \mathrm{O}_{5}$ Thin Films Materials Science in Semiconductor Processing 16 2013: pp. 256-262. https://doi.org/10.1016/j.mssp.2012.11.001

3. Benmoussa, M., Ibnouelghazi, E., Bennouna, A., Ameziane, E.L. Structural, Electrical and Optical Properties of Sputtered Vanadium Pentoxide Thin Films Thin Solid Films 265 1995: pp. 22-28. https://doi.org/10.1016/0040-6090(95)06617-9

4. Krishna, M.G., Debauge, Y., Bhattacharya, A.K. X-ray Photoelectron Spectroscopy and Spectral Transmittance Study of Stoichiometry in Sputtered Vanadium Oxide Films Thin Solid Films 312 1998: pp. 116-122. https://doi.org/10.1016/S0040-6090(97)00717-7

5. Murawski, L., Gledel, C., Sanchez, C., Livage, J., Audiers, J.P. Electrical Conductivity of $\mathrm{V}_{2} \mathrm{O}_{5}$ and $\mathrm{Li}_{x} \mathrm{~V}_{2} \mathrm{O}_{5}$ Amorphous Thin Films Journal of Non-Crystalline Solids 89 1987: pp. $98-106$. https://doi.org/10.1016/S0022-3093(87)80324-1

6. Kumar, Y.V., Reddy, M.V.R., Reddy, K.N. Preparation and Optical Characterization of $\mathrm{V}_{2} \mathrm{O}_{5}$ Thin Films International Conference on Nanoscience, Engineering and Technology(ICONSET), Chennai India 2011: pp. 244-246.
https://doi.org/10.1109/ICONSET.2011.6167931

7. Vijayakumar, Y., Sayanna, R., Ramana Reddy, M.V. Annealing Effects on Structural, Optical and Electrical Properties of $\mathrm{V}_{2} \mathrm{O}_{5}$ Thin Films by Dip Coating Asian Journal of Applied Sciences 7 (8) 2014: pp. 753-760. https://doi.org/10.3923/ajaps.2014.753.760

8. Julien, C., Haro-Poniatowski, E., Camacho-Lopez, M.A., Escobar-Alarcon, L., Jimenez-Jarquin, J. Growth of $\mathrm{V}_{2} \mathrm{O}_{5}$ Thin Films by Pulsed Laser Deposition and Their Applications in Lithium Microbatteries Materials Science and Engineering: B 65 1999: pp. 170-176.

9. Vijayakumar, Y.,

Ganesh Kumar, M., Ramana Reddy, M.V., Rayappan, J.B.B. Nanostructured Flower Like $\mathrm{V}_{2} \mathrm{O}_{5}$ Thin Films and its Room Temperature Sensing Characteristics Ceramics International 41 2015: pp. $2221-2227$. https://doi.org/10.1016/j.ceramint.2014.10.023

10. Akl, A.A. Thermal Annealing Effect on the Crystallization and Optical Dispersion of Sprayed $\mathrm{V}_{2} \mathrm{O}_{5}$ Thin Films Journal of Physics and Chemistry of Solids 71 2010: pp. $223-229$. https://doi.org/10.1016/j.jpcs.2009.11.009

11. Zhu, M., Liu, L., Hou, Y., Yan, H., Xu, J.B., Shao, M., Chen, X. Effects of Sputtering Pressure on Compositions and Structures of Fresnoite Thin Films Physica B 355 2005: pp. $100-105$. https://doi.org/10.1016/j.physb.2004.10.028

12. Vijayakumar, Y., Shanmukhi Jyothi, D., Nagaraju, P., Ramana Reddy, M.V. Structural, Electrical and Optical Properties of Spray Deposited $\mathrm{V}_{2} \mathrm{O}_{5}$ Thin Films on Glass Substrates Physics and Chemistry of Glasses - European Journal of Glass Science and Technology Part B 57 (1) 2016: pp. $37-41$. https://doi.org/10.13036/17533562.57.1.019

13. Eman Abid, M., Inaam Abdulmajeed, M., Kadhim Aadim, A. Effect of Annealing Temperature on the Structural and Optical Properties of Nanocrystalline Strontium Titanate Thin Film Prepared by PLD International Journal of Innovative Research in Science, Engineering and Technology 2 2013: pp. 9.

14. Vasanth Raj, D., Ponpandian, N., Mangalaraj, D., Viswanathan, C. Effect of Annealing and Electrochemical Properties of Sol-Gel Dip Coated Nanocrystalline $\mathrm{V}_{2} \mathrm{O}_{5}$ Thin Films Materials Science in Semiconductor Processing 16 2013: pp. 256-262. https://doi.org/10.1016/j.mssp.2012.11.001

15. Oksuzo $\breve{g l u, ~ R . M ., ~ B i l g i c, ~ P ., ~ Y ı l d ı r ı m, ~ M, ~ D e n i z, ~} \mathbf{O}$. Influence of Post-Annealing on Electrical, Structural and Optical Properties of Vanadium Oxide Thin Films Optics \& Laser Technology 48 2013: pp. 102-109. https://doi.org/10.1016/j.optlastec.2012.10.001

16. Nadarajah, K., Ching Yern, C., Yong Tan, C. Influence of Annealing on Properties of Spray Deposited ZnO Thin Films Journal of Nanomaterials 2013: pp. 146382. http://dx.doi.org/10.1155/2013/146382 